lost, I instantly proceeded to take blood from the arm, by making a large orifice, from which, in a very short space of time, forty ounces of blood flowed. I then waited a few minutes, hoping that some good effect would follow so copious and sudden a loss of blood, but had the mortification to see no favourable change in the frightful character of the symptoms. I therefore removed my thumb from the opening in the vein, where I had with much difficulty managed to keep it during the violent struggles of the patient, and allowed thirty ounces more to escape in the same rapid manner. This second bleeding had at once a marked and beneficial effect, as the convulsions almost immediately ceased, a more natural expression of countenance returned, and she was shortly restored to a condition of apparent consciousness. I then removed most of her hair, and applied a bladder half filled with pounded ice to the head, and bottles of hot water to her feet. On making the usual examination, I found the os uteri about half dilated, but exceedingly rigid and tense, as were also the external parts. Just at this time $I$ had the satisfaction of seeing my friend Mr. Musgrave enter the room, followed shortly afterwards by Dr. Tyler Smith, whom I had sent for immediately on perceiving the serious nature of the case.

There was now an almost entire absence of uterine pain. The abdomen was carefully manipulated, but no movements of the foetus could be excited or detected, though its rounded mass could be felt within the uterus. The foetal heart could not be heard upon auscnltation, so that it was concluded that the foetus was probably already dead. As there was a calm in the convulsions, it was resolved to delay the performance of turning or craniotomy until more imperatively called for. It was agreed that it would be desirable to rupture the membranes as soon as practicable, and allow the liquor amnii to escape, so as to diminish the uterine distention. As there was still much general excitement of system, the pulse numbering 110 in a minute and hard, and the os uteri and other tissues continuing very rigid, in spite of the previous depletion, it was felt necessary to follow up the antiphlogistic plan, and with that view it was decided to try the full effect of tartarized antimony, as the medicine best adapted to fulfil the indications required. Accordingly nine grains of the salt were dissolved in six ounces of the camphor mixture, and an ounce of this solution was administered every hour during the day : such was the tolerance of the remedy, that not even the slightest nausea was induced by it, but it had the happiest effect in softening and relaxing. the previously rigid condition of the parts. The labour pains, which had been quite suspended for about four hours, returned gradually about one o'clock, and I availed myself of the first opportunity which offered to rupture the membranes, when about a pint of water flowed away. I may here mention, that although no further convulsions occurred, she continued in a torpid and half-comatose state, the sense of vision especially being very imperfect. The uterine efforts became now strong and effective, but owing to the slow dilatation of the os uteri, the anterior lip was pushed down in front of the head in its passage through the pelvis, reaching almost to the os ex. ternum. I succeeded, however, at about seven in the evening, aided only by the natural efforts, in delivering her of a still-born female child, and having waited about twenty minutes, and no pain coming on, I extracted the placenta, which was partly in the vigina, and soon had the satisfaction of feeling the uterus well and firmly contracted. Dr. Tyler Smith saw her again with me in the evening, and a draught, containing one third of a grain of morphia and three grains of camphor, was administered, which had the effect of calm. ing the nervous irritability and restlessness, which had been for some time increasing. She slept profoundly the whole of the night, and on visiting her next morning I found her with a quiet intelligent smile on her countenance; her pulse 96 and soft; the skin moist and comfortable; the head free from pain, but feeling rather heavy; and having no recollection whatever of anything which had occurred during the previous twenty-four hours. I ordered her still to continue the ice-cap to the head, and to take a saline draught containing a diminished quantity of tartarized antimony every four hours.

On Friday, the 5th, she had a dose of calomel and colocynth, followed in a few hours by a draught of senna and salts, which cleared out the bowels very effectually. A purgative was afterwards exhibited every alternate day. She continued steadily to improve without a bad symptom, and I have the satisfaction to state that she soon perfectly recovered. The secretion of milk on the fourth day was very abundant, and proved rather troublesome for some short time.
I must not omit to notice, that on testing the urine $I$ found in it no trace of albumen, nor was there any cedematous swelling of the legs-a fact of some importance in reference to the modern theory with regard to the nature of these congestive diseases of the bruin, as it affords conclusive evidence that albuminuria does not universally obtain in these affections.

This case, I think, presents several other features of considerable interest to the practical obstetrician and to the profession generally. In the first place, it serves to confirm the imperative necessity of large and adequate depletion in the congestive variety of this formidable disease, affording at the same time ample proof of its undoubted safety and success. It also furnishes a remarkable example of the tolerance of tartar emetic-a fact long well established in reference to its use in pneumonia and some other pulmonary affections, but not, that $I$ am aware of, to the same extent in cerebral disorders as this case so strongly illustrates, a grain and a half having been taken every hour for eight consecutive hours without the least nansea resulting from it. While speaking of this valuable medicine in connexion with this class of affections, it may not be out of place to add, that I have employed it with marked benefit in combination with camphor and morphia. (aided by cold applications to the head, and preceded by active purgation and leeches to the temples, in two very severe cases of puerperal mania. General bloodletting being here for the most part inadmissible, it is very desirable to possess a remedy so available as this proved in both the instauces referred to in controlling the excited state of the circulation, and in tranquillizing the extreme irritability of the nervous system both which conditions are so constantly present in the more active forms of this distressing malady.

Clifton-road, St. John's-wood, 1852 .

\section{SINGULAR CASE OF ASPHYXIA.}

\section{By GEORGE PARKER MAY, M.D. Edin.}

I RECEIVED an urgent request (on April 27th, 1852,) to visit a young man two miles from hence, who was stated by the messenger to have been choked by being "rolled in bran." On reaching the spot, I found a lad about eighteen years of age extended on a bed, apparently quite dead. The bystanders informed me that he had ceased to breathe about twenty minutes. The countenance was pallid, the lips somewhat livid. I at onse opened the trachea immediately below the cricoid cartilage, cutting through the three first rings, and endeavoured to restore respiration by artificial means, but without success. The case became the subject of judicial investigation, and in compliance with an order from the coroner for the county, I made an examination of the body sixteen hours after death. The thorax and abdomen retained a sensible amount of warmth; the heart was in all respects healthy, ventricles empty, and the venæ cavæ distended with black blood; the right lung was extensively adherent to the costal pleura; the parenchymatous structure of both lungs appeared to be entirely normal, but when cat into, a considerable quantity of reddish, frothy fluid exuded from them when gently squeezed. The larynx and trachea were carefully removed from their attachments, and on slitting up the former, some particles of coarse pollard were visible in its cavity, principally around and in the ventricles. Similar particles were observed on the lining membrane of the trachea. At the bifurcation of the tube a considerable mass of this substance was found occupying its whole calibre. The left bronchus was entirely filled with pollard, the right nearly so, and their subdivisions, as far as they could be traced into the substance of the lungs, were full of the same material. More than a tablespoonful was extracted from the bronchi and their larger ramifications. The brain presented nothing abnormal, excepting a somewhat congested condition; this probably would have been more marked had this viscus been first examined, as a large quantity of blond flowed from the descending cava on separating the heart and lungs from the thoracic cavity.

It appeared from the evidence adduced at the inquest, that the deceased was, by way of joke, forced head-dow nwards into a sack containing about a bushel of pollard, by two of his fellowlabourers on the farm. According to the testimony of $\in$ ane of the parties, who were at the same time the perpetrators and the only witnesses of the outrage, the mouth of the sack was tied with rope-yarn round the legs of the lad. This was almost immediately cut, and the boy released from the sack. He was reported to be black in the face and frothing at the snouth, but besame sufficiently sensible to drink a small quantity of water. When removed 
from the granary, where the occurrence took place, to his bedroom, he was breathing with difficulty; was entirely insensible during the time that he lived, which was about a quarter of an hour after his removal and about twenty minutes after he was extricated from the sack.

The jury returned a verdict of "manslanghter" against the parties implicated in the transaction, and they were committed on the coroner's warrant for trial at the ensuing assizes.

Maldon, May, 1852.

\section{a ftirror}

OF THE PRACTICE OF

\section{MEDICINE AND SURGERY IN THE HOSPITALS OF LONDON.}

Nulla est alia pro certo noscendi via, nisi quam plurimas et morborum, et dissectionum historias, tum aliorum proprias, collectas habere et inter comparare.-Morgagni, De Sed. et Caus. Morb., lib. iü. Procmium.

\section{ST. BARTHOLOMEW'S HOSPITAL.}

Carcinoma of the Rectum; Artificial Anus by Amussat's method; Temporary Relief; Death; Autopsy.

(Under the care of Dr. Burrows and Mr. Paget.)

WE called attention a little time ago to some cases of unconquerable obstruction of the intestinal canal, which were treated in this hospital (THE LANCET, vol. ii., 1851, p. 128). It will be remembered that it was not thought advisable, in these instances, to resort to operative measures, and that on post-mortem examinations, a state of parts was found which might in some degree have justified an attempt of creating an artificial outlet for the pent-up fæcal matter. We have now to offer a few details of a case in which Mr. Paget actually made an artificial anus in the groin, with temporary benefit; and though the patient did not finally recover, it is of importance that such cases should be put upon record, as it may happen that a similar operation, under more favourable circumstances, might prolong life for an indefinite period.

There is doubtless some risk in making an artificial outlet, either for the fæces or urine, but it has appeared to some ex perienced surgeons that this risk would perhaps be less im portant if such operations were performed earlier, and before the patient is completely reduced by pain, peritonitis, and the administration of strong purgatives, or other medicines. In fact, the question is simply this: is the danger of making an artificial anus or urethra greater in a given instance than allowing the obstruction to continue, relying in the latter case either on the efficacy of remedies or the powers of nature?

It is clear that in such a disease as carcinoma of the rectum, the patient dies of the maliguant disease, or the obstinate constipation to which the cancerous affection may give rise. But the fatal issue is more rapid by the effects of the obstruction than those of the cancer, so that in cases of this kind an artificial opening in the loins may very properly be made.* In intestinal constriction by band, congestion, fibrinous deposit, or any adventitious change which admits of spontaneous repair, or rectification by surgical means, a lumbar anus may be looked upon as a temporary outlet, the great advartige of which is to forestall the evil effects of a prolonged retention of fecal matter, and afford a realy exit to it, while the portion of the intestinal canal which is the seat of the obstruction untergo:s (in favourable cases) such changes as will tend to re-estalilish the continuity of the wole tract.

There is certainly some analogy between puncturing the bladder by the rectum, making an artificial anus in the loins, and performing tracheotomy. We want, by these operations, to facilitate the exit of certain products or the entrance of air, in order to ward off a fata! issue, these oper itive measures being princinally intended to afford temporary reilef. But the surgeon, after following this line of practice, turns his $n$ hole attention to the quiescent state to which the affected organs are brought by the artificial in-or out-let, and endeavours to take advantage of this truce, if we may so speak, to favour the return of healthy function in the digestive, urinary, or respiratory organs.

* See a case of the same nature treated by Mr. Gay at the Royal Free Hospital. THE LANcer, vol. i., is5i, p. 623 .
The great misfortune is, of course, that we are exposed in fatal cases to the displeasure of the patient's friends, who never fail to attribute to the operation, and not to the disease, the unfavourable termination which may take place. This injustice on the part of the public has very probably induced surgeons in many instances to postpone operations, which at an early period might have been instrumental to the prolongation of life. We refrain from saying more just now, for we fully expect having very soon an opportunity of returning to this subject, which is in several respects highly important, and proceed to offer a few details of the present case, as noted by Mr. Callender, the dresser of the patient.

Sarah $\mathrm{P}-$, about forty-five years of age, was admitted July 27th, 1851, into Faith ward, nnder the care of Dr. Burrows. The patient was in a state of great exhaustion and emaciation; her lips and teeth were covered with sordes, the respiration laboured, and the skin warm, except towards the extremities; the pulse was 124, small and soft; the tongue dry, brown on the dorsum, and red at tip and edges; the thirst urgent, and the appetite quite gone. There was no nausea on admission, but there had been sickness and romiting on the previous morning; the bowels bad been confined for nice days, and no urine roided for about twelve hours. On examination, the abdomen was found hard, distended, and tympanitic, the integuments covering it firm and glazed, the cavity being the seat of intense pain, principally referred to the region of the cacum, and occurring in paroxysms, with violent peristaltic movements of the intestines. In the rectum, a firm tumour was felt projecting into the cavity of the bowel, depressed in the centre, and seemingly springing from the hollow of the sacrum. The tumour descended to within about four inches of the anal orifice, between which and the abnormal growth the rectum was healtby, but of a larger calibre than usual. The uterus had been in a prolapsed condition for a long time past.

The patient, on being questioned, stated that she was a widow, the mother of two children, that her labours had been natural, and that she generally enjoyed good health, though now and then, for the last eight years, suffering from constipation. Within about one year, the stoo's had been scanty, and consisting of small worm-like pieces of fæcal matter. The present abdominal obstruction commenced, as the patient says, nine days before admission, but there was reason to believe that eleven days bad passed since the last evacuation. She has had violent pain in the abdomen ever since, and the most active aperient treatment has not overcome the constipation.

Dr. Burrows directed the introduction of a long tuhe, which, however, gave no relief; a drop of croton oil was therefore given. As this had no effect, at seven - $0^{3}$ elock in the evening, Dr. Burrows and $\mathrm{Mr}$. Paget decided, in consultation, that an artificial outlet, for the facal matter should be made in the loins by opening the colon.

Chloroform was administered; and while the patient lay on her chest and abdomen, Mr. Paget made an incision over the descending colon, about four inches in length, and extending from the extremity of the last rib to the crest of the ilium. The latissimus dorsi, external oblique, lower and outer part of the quadratus lumborum, and the aponeurosis of the internal oblique, were successively divided, and found much thinned by the distention. The intestine was now exposed, and, being very tense, was easily opened by an incisiou about half an inch in length. A copious discharge of fluid freal matter and flatus instantly took place; and as the bowel bulged ont considerably; it was secured to the margins of the external wound by four ligatures, and the patient conveyed to bed. During the oneration, the pulse continued steadily at 112 , and rather improved in volume towards the conclusion. The patient was given some ether in camphor mixture, to be repeated every four hours; and she was to have an opiate when necessary.

It was found, on the next day, that she had slept tolerably the wonnd had allow: ed a constant and copious discharge of frcal matter; the patient felt much easier, and had not complained of pain since the operation; pulse 96 , sightly decreased in volume; tongue les $\mathrm{dry}$, aud covered on one side with a thick white fur; appetite slightly returned. The wcund looked well, but the mucous membrane of the bowel was everted, and projected through the external wound; the lerneated membrane was however, easily returned, and kept in its place by a piece of sponge. 'Twenty ounces of high-coloured urine were drawn off by the catheter. The diet was to consist of arrowroot in milk; betf-tea; and wine.

The patient was quite free from pain during the whole of this day, and went on taking a fair amount of nourishment. There was no nausea, and partly solid fæeal matter continued to be discharged from the wound. The abdomen was at the same time flaccid, and tolerant of pressure. 